\title{
Hitting "turbo" after the race is done: Subpulmonic support in failed Fontan circulation
}

\author{
Kyle W. Riggs, MD, and David L. S. Morales, MD
}

\footnotetext{
From the Department of Cardiothoracic Surgery, Cincinnati Children's Hospital Medical Center, Cincinnati, Ohio.

Disclosures: Dr Morales discloses the following: consultant and instructor for Berlin Heart, Inc; proctor and consultant for Syncardia, Inc; national primary investigator for the 50/50cc Syncardia Total Artificial Heart Food and Drug Administration trial; consultant for Medtronic Inc (HeartWare Division); and consultant for Abbott Medical Inc (Thoratec Division). Dr Riggs has nothing to disclose with regard to commercial support.

Received for publication May 14, 2018; revisions received May 14, 2018; accepted for publication May 14, 2018; available ahead of print June 27, 2018.

Address for reprints: Kyle W. Riggs, MD, 3333 Burnet Ave, Cincinnati, OH 45229 (E-mail: kyle.riggs@cchmc. org).

J Thorac Cardiovasc Surg 2018;156:1957-8

$0022-5223 / \$ 36.00$

Copyright $(2018$ by The American Association for Thoracic Surgery

https://doi.org/10.1016/j.jtcvs.2018.05.039
}

The article by Broda and colleagues ${ }^{1}$ represents an excellent compilation of the previous efforts at improving the subpulmonic blood flow after the Fontan procedure. As the authors describe, there has been a significant number of investigations into the logical concept of re-creating what evolution has created over millions of years, a 2ventricle heart for humans. However, there are a multitude of unique issues, which the Fontan circulation presents, and any device that requires deconstructing the cavopulmonary connection to augment forward flow and decrease venous congestion represents a significant surgical burden. Unfortunately up to now, most in vivo devices have failed to achieve any real benefit, but several existing concepts show future promise of being able to augment pulmonary blood flow for long durations of time. Although there is currently only one instance of a subpulmonic assist device successfully supporting a failing Fontan circulation to reverse end-organ dysfunction before transplantation, Broda and colleagues ${ }^{1}$ agree that elective placement of subpulmonic "support could become the 'fourth stage' of single ventricle palliation." ${ }^{2,3}$ If this is to become the next step of treating single-ventricle pathologies, then not only is device development and implantation strategy critical, but we must also consider the optimal timing for this intervention.

The primary issue with the concept of assisting subpulmonic flow is that the Fontan circulation typically fails at multiple levels as the body develops several maladaptive responses to the unusual passive flow circulation. These changes lead to an abnormal pulmonary vasculature, compromising blood flow into a systemic ventricle, which often develops a restrictive physiology from years of underfilling. Long-term studies have shown Fontan survivors to have preserved systolic function in $73 \%$ of patients and diastolic dysfunction in $72 \%$ further emphasizing that this group is quite unique from patients we commonly place on mechanical

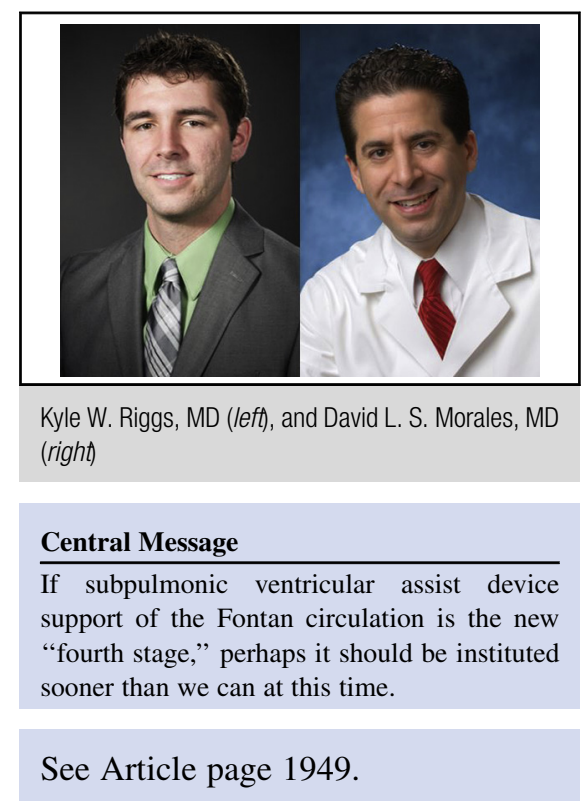

circulatory support. ${ }^{4}$ The diastolic dysfunction is likely due to a chronic preload deprivation and impaired ventricular filling, which worsens as patients get further from their Fontan surgery. ${ }^{5}$ Therefore, when the features of circulatory failure become present, forcing blood through a pulmonary vasculature that has already developed chronic pathology into a restricted ventricle would appear to be a futile attempt to fix a broken system after it's too late. This definitely would not appear to be an effective strategy for chronically supporting these patients. Conversely, instituting subpulmonic support early after the Fontan procedure could provide ample blood flow to prevent some of the maladaptive responses and pathophysiological changes that occur. If we could find a means of safely augmenting subpulmonic blood flow for long durations of time, perhaps soon after Fontan completion, then we could "turbocharge" the Fontan. A "turbo Fontan circulation" has the potential to avoid the issues from chronic passive flow by manufacturing the state evolution had intended, a "biventricular circulation."

\section{References}

1. Broda CR, Taylor DA, Adachi I. Progress in experimental and clinical subpulmonary assistance for Fontan circulation. J Thorac Cardiovasc Surg. 2018;156:1949-56. 
2. Jaquiss RD, Aziz H. Is four stage management the future of univentricular hearts? Destination therapy in the young. Semin Thorac Cardiovasc Surg Pediatr Card Surg Annu. 2016;19:50-4.

3. Prêtre R, Häussler A, Bettex D, Genoni M. Right-sided univentricular cardiac assistance in a failing Fontan circulation. Ann Thorac Surg. 2008;86: 1018-20.
4. Anderson PA, Sleeper LA, Mahony L, Colan SD, Atz AM, Breitbart RE, et al. Contemporary outcomes after the Fontan procedure: a Pediatric Heart Network multicenter study. J Am Coll Cardiol. 2008;52:85-98.

5. Giridharan GA, Ising M, Sobieski MA, Koenig SC, Chen J, Frankel S, et al. Cavopulmonary assist for the failing Fontan circulation: impact of ventricular function on mechanical support strategy. ASAIO J. 2014;60:707-15. 